The

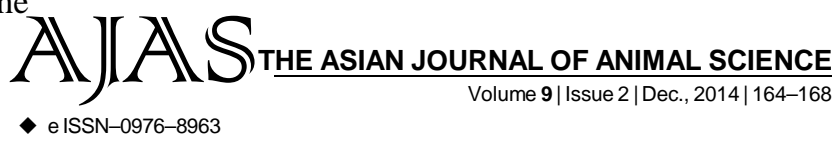

DOI : 10.15740/HAS/TAJAS/9.2/164-168

Visit us | www.researchjournal.co.in

RESEARCH ARTICLE.........

\title{
Quality evaluation of extruded fishery products packed in normal and standard multilayer packaging under nitrogen infusion
}

\author{
SUBHA GANGULY, SREEKANTA SARKAR AND RANJIT BORDOLOI
}

Author for Corresponding -

SUBHA GANGULY

AICRP on Post Harvest

Technology (ICAR), Department

of Fish Processing Technology,

Faculty of Fishery Sciences, West

Bengal University of Animal and

Fishery Sciences, Chakgaria,

KOLKATA (W.B.) INDIA

Email: aicrponpht.kolkata@gmail.com

See end of the article for

Coopted authors'
ABSTRACT...... Particular multilayer packaging material (consisting of LDPE, metalized polyester and polythene) and LDPE was selected and trials were performed and standardized on the property of the pouch to withstand the nitrogen pressure under gas infused packaging state containing the extruded fishery products. The thickness of the standard packaging material was measured to be $65 \mu$. The study interpreted a significant alteration in proximate composition $(\mathrm{P}>0.05)$. On the contrary, moisture and ash content including overall sensory parameters did not vary significantly $(\mathrm{P}<0.05)$. The product texture after storage for 3 months as stored in standard packaging material under nitrogen infusion revealed firmness $3904.2 \pm 40.97 \mathrm{~g}$, toughness $19411.61 \pm 583.91 \mathrm{~g} . \mathrm{sec}$. was not altered significantly when tested by texture analyser at 15 Days regular intervals. But, in case of normal packaging, the materials showed drastic alteration in the moisture content, texture profile and sensory parameters. The microbiological analysis revealed no marked contamination and alteration of the extruded product quality when stored in standard packaging material under nitrogen infusion thereby favoring its consumer acceptance. In the present study, the storage study of the extruded fishery product revealed the shelflife of the extruded fishery product up to 3 months.

KEY WORDS...... Extruded Products, Fish, Multilayer packaging, Shelf-life

HOW TO CITE THIS ARTICLE - Ganguly, Subha, Sarkar, Sreekanta and Bordoloi, Ranjit (2014). Quality evaluation of extruded fishery products packed in normal and standard multilayer packaging under nitrogen infusion. Asian J. Animal Sci., 9(2) : 164-168.

ARTICLE CHRONICLE - Received : 17.09.2014; Revised : 05.11.2014; Accepted : 20.11.2014 